\title{
Comparison of dexmedetomidine, midazolam, and propofol as an optimal sedative for upper gastrointestinal endoscopy: A randomized controlled trial
}

\author{
Sumanth Samson, Sagiev Koshy George, B. Vinoth ${ }^{1}$, Mohd Saif Khan, Bridgitte Akila ${ }^{2}$ \\ Departments of Anesthesiology, ${ }^{1}$ Gastroenterology and ${ }^{2}$ Biostatistics, Pondicherry Institute of Medical Sciences, Puducherry, India
}

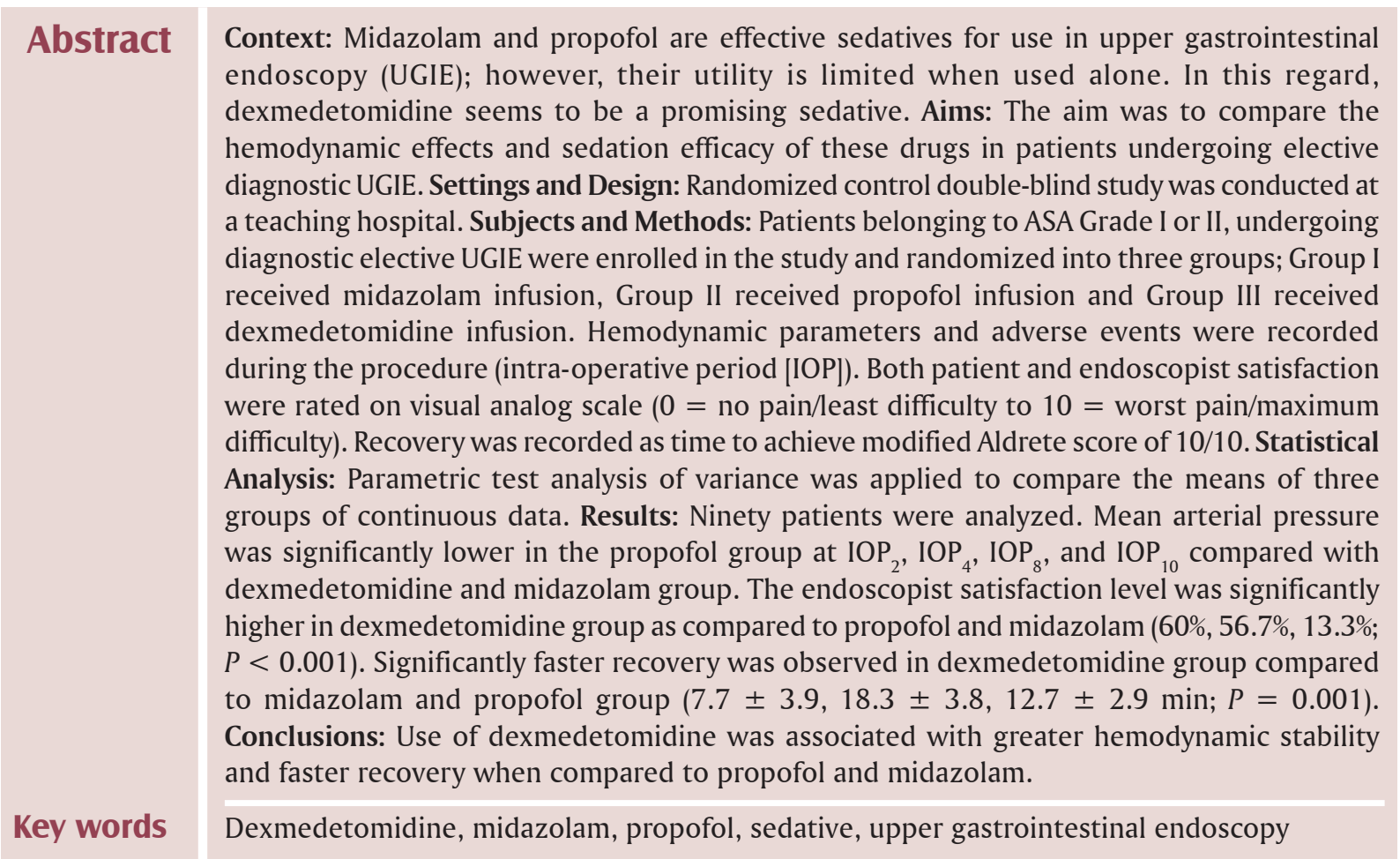

\section{Introduction}

The development of upper gastrointestinal endoscopy (UGIE) has greatly expanded the diagnostic and therapeutic

\begin{tabular}{|l|c|}
\hline \multicolumn{2}{|c|}{ Access this article online } \\
\hline \multirow{2}{*}{$\begin{array}{l}\text { Website: } \\
\text { www.jdeonline.in }\end{array}$} & Quick Response Code \\
\hline \multirow{2}{*}{$\begin{array}{l}\text { DOI: } \\
\text { 10.4103/0976-5042.144826 }\end{array}$} & \\
\hline
\end{tabular}

capabilities of gastroenterologists. Routine UGIE is the standard practice to diagnose esophageal, gastric and duodenal diseases. This is an invasive procedure and the examination, usually, lasts for about 10 mins with very low complication rates. The procedure may be performed with or without conscious sedation using topical pharyngeal anesthesia alone. But, patient's tolerance to procedure and endoscopist's satisfaction increase when sedation is used along with topical pharyngeal anesthesia. ${ }^{[1]}$ Moreover, judicious use of sedation can alleviate the sympathetic response (rise in heart rate and systolic blood pressure) to the procedure. ${ }^{[2]}$ Numerous agents are available for moderate sedation in endoscopy. Sedation practices may vary from 
country to country and from hospital to hospital that could influence the endoscopists' attitude. ${ }^{[3]}$ Furthermore, choice of a particular sedative agent depends on its availability, cost and experience of endoscopist and patient with that sedative agent.

The goals of sedation are analgesia, amnesia, immobility during the procedure, ability to complete the procedure and quick patient recovery to pre-procedure level of consciousness. ${ }^{[4]}$ Midazolam and Propofol are the most widely used sedative medications during UGIE. Midazolam is favored due to its potent amnestic properties, anxiolytic effect and a short elimination half-life. ${ }^{[3]}$ Dexmedetomidine, an $\alpha_{2}$-agonist, has been used widely for sedoanalgesia in diagnostic and therapeutic procedures, and its use is progressively increasing. ${ }^{[5]}$ However, the use of dexmedetomidine in adults undergoing UGIE has not been completely evaluated. Until date, no study has compared three anesthetic agents (solely) in diagnostic UGIE and data from Indian continent are scarce. This study aimed to compare the hemodynamic effects and to assess sedation efficacy of these drugs in patients undergoing elective UGIE.

\section{Subjects and Methods}

This randomized control double-blind study was conducted at a tertiary care level teaching hospital over a period of two years after obtaining Ethical Committee clearance and registration of trial (No. REF/2013/10/005800). The endoscopist, the investigator, and recovery room personnel remained blinded while the anesthesiologist was not blinded to the patient's sedation regimen. Adult patients aged 18-60 years and who belong to American Society of Anesthesiologists [ASA] physical status classification system class I or II, undergoing diagnostic elective UGIE were enrolled in the study. Exclusion criteria were systemic hypertension, bleeding diathesis, prior gastric surgeries, psychiatric diseases or long-term antipsychotic drug therapy, chronic use or addiction to opiates or sedatives, presence of neoplastic or other serious concomitant diseases, previous adverse reactions to any medication used in the present study, baseline systolic blood pressure $<90 \mathrm{mmHg}$, allergy to eggs, history of sleep apnea and anticipated difficult intubation.

\section{Randomization}

After obtaining written informed consent, patients were randomized into one of the three groups using a computer-generated randomization list: Group I received an infusion of $0.03 \mathrm{mg} / \mathrm{kg}$ loading dose of Midazolam (Benzosed, Troikaa Pharmaceuticals Ltd.), followed by $0.06 \mathrm{mg} / \mathrm{kg} / \mathrm{h}$ as continuous infusion. Group II received an infusion of $1 \mathrm{mg} / \mathrm{kg}$ loading dose of Propofol (Troypofol, Troikaa Pharmaceuticals Ltd.), followed by $3 \mathrm{mg} / \mathrm{kg} / \mathrm{h}$ as a continuous infusion. Group III received an infusion of $1 \mu \mathrm{g} / \mathrm{kg}$ loading dose of dexmedetomidine (Dextomid, Neon Laboratories Ltd.) over $10 \mathrm{~min}$, followed by $0.5 \mu \mathrm{g} / \mathrm{kg} / \mathrm{h}$ as a continuous infusion. Inj. Fentanyl $25 \mu \mathrm{g}$ was administered intravenously as rescue sedation for all the three groups as and when required. All medications in the syringe and the infusion lines were remained covered with white paper ensuring adequate blinding.

\section{Procedure}

Pre anesthetic check-up was conducted prior to procedure during which patients were explained about the visual analogue scale (VAS) and informed consents were obtained. All the patients were kept nil per oral 8-10 h prior to the procedure. Upon arrival to the endoscopy suite, monitoring (electrocardiography, pulse oximetry, NIBP) was started and continued until shifting out to the recovery area. The baseline values of HR, mean arterial pressure (MAP), oxygen saturation of hemoglobin $\left(\mathrm{SpO}_{2}\right)$ and respiratory rate $(\mathrm{RR})$ were recorded. Topical pharyngeal anesthesia was administered by spraying metered dose of $10 \%$ lignocaine. Following peripheral IV access, patients were premedicated with injection glycopyrrolate $10 \mu \mathrm{g} / \mathrm{kg}$. During the procedure, monitoring of $\mathrm{HR}, \mathrm{MAP}, \mathrm{SpO}_{2}$ and $\mathrm{RR}$ was continued every $2 \mathrm{~min}$ for the first $10 \mathrm{~min}$, thereafter every $5 \mathrm{~min}$ until end of the procedure. When the patient achieved a desired level of sedation level of 2-4 on observer assessment alertness/sedation scale, endoscope was introduced. ${ }^{[6]}$ Time to reach the desired sedation level was also recorded. Occurrence of adverse events like hypertension, hypotension, desaturation, apnea, gagging and retching was also recorded during the procedure. All endoscopies were carried out by a single operator using a GIF-H180 gastroscope (Olympus ${ }^{\circledR}$ ).

The Patients' satisfaction regarding discomfort (pain and gagging) during the procedure was assessed using the VAS in the recovery room. All patients were asked to place a vertical mark on a $10 \mathrm{~cm}$ straight line labeled only with descriptors at each end to represent procedural pain, $(0=$ no pain, $10=$ worst pain imaginable). Endoscopist satisfaction regarding retching and difficulty during the procedure was assessed using VAS ( $0=$ no retching/difficulty, to $10=$ maximum retching/difficulty). Recovery from sedation was assessed using modified Aldrete score at 5 min after removal of the endoscope and every $5 \mathrm{~min}$ thereafter until a discharge score of 10/10 was reached. ${ }^{[7]}$

\section{Statistical analysis}

The data were entered in Epi Info 7 (Centers for Disease Control and Prevention Atlanta, GA) software and analyzed using SPSS (SPSS Inc., Chicago, Illinois, USA) 17.0 for Windows statistical software. Continuous data were expressed as mean and standard deviation. Dichotomous and categorical data were described using percentages. Analysis of variance was applied to compare the means of three groups of continuous data. Chi-square test and Fisher's exact test were applied to compare categorical and dichotomous data. To compare the means of two groups, Student's $t$-test with multiple comparisons was applied. 


\section{Results}

We screened 103 patients for inclusion in the study as shown in the CONSORT flow diagram [Figure 1]. Ninety subjects were randomized into three groups of 30 each. There were no statistically significant differences between the groups with regard to age, gender, height, weight, ASA class, hemodynamic variables and requirement of fentanyl [Table 1]. The MAP was significantly lower in the propofol group at $\mathrm{IOP}_{2}, \mathrm{IOP}_{4}, \mathrm{IOP}_{8}$, and $\mathrm{IOP}_{10}$ compared to dexmedetomidine and midazolam groups [Figure 2a]. There were no significant differences in mean RR and mean oxygen saturation among three groups [Figure $2 b$ and $c]$. None of the patients developed desaturation or bronchospasm. Mean doses of midazolam, propofol and dexmedetomidine used were $7.8 \mathrm{mg} \pm 3.8 \mathrm{mg}, 94.05 \mathrm{mg} \pm 6.1 \mathrm{mg}$, and $62.2 \mu \mathrm{g} \pm 5.4 \mu \mathrm{g}$ respectively. The patient satisfaction level (measured by VAS) of grade 1 (highest level of satisfaction) was significantly higher in midazolam group as compared to dexmedetomidine group $(93.3 \%, 40 \% ; P<0.001$, $t$-test with multiple comparison), whereas no statistically significant differences in patient satisfaction were noted between (i) propofol and dexmedetomidine and (ii) propofol and midazolam $(P>0.05)$. The endoscopist satisfaction level of grade 1 (highest level of satisfaction) was significantly higher in the dexmedetomidine group than midazolam group $(60 \%, 13.3 \% ; P<0.001$, $t$-test with multiple comparisons). Similarly, propofol demonstrated significantly higher endoscopist satisfaction level as compared to midazolam $(56.7 \%$ vs. $13.3 \% ; P<0.001, t$-test with multiple comparisons). Recovery was significantly faster in the dexmedetomidine group than midazolam and propofol group $(7.7 \pm 3.9,18.3 \pm 3.8,12.7 \pm 2.9 ; P<0.001)$. The incidence of adverse events (gag and discomfort) was not significantly different among three groups [Table 2].

\section{Enrolment}

Assessed for eligibility $(\mathrm{n}=103)$

Excluded (n=5)

Not meeting inclusion criteria $(n=6)$

Declined to participate $(n=2)$

Other reasons $(n=0)$

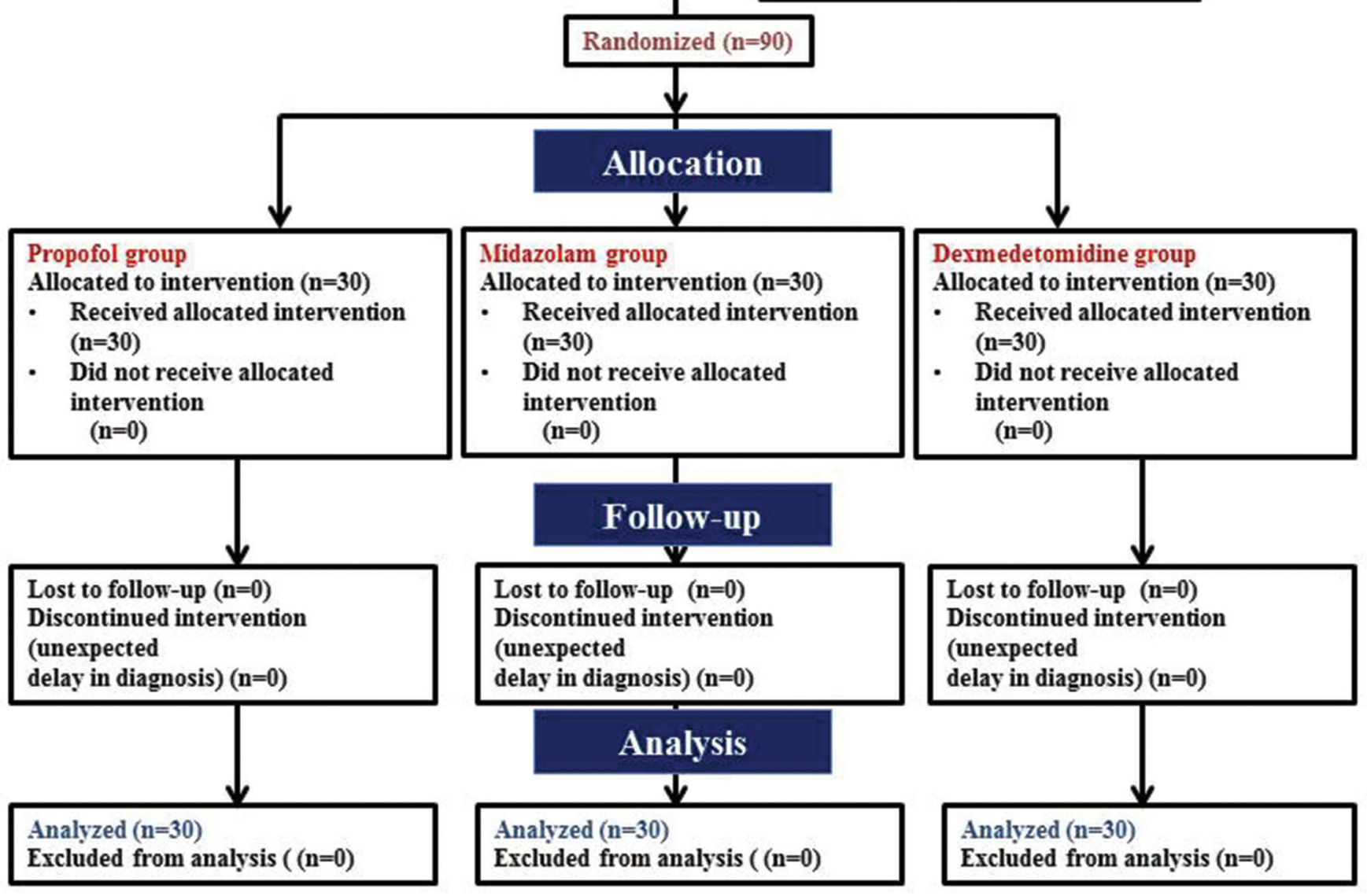

Figure 1: Consort flow chart 


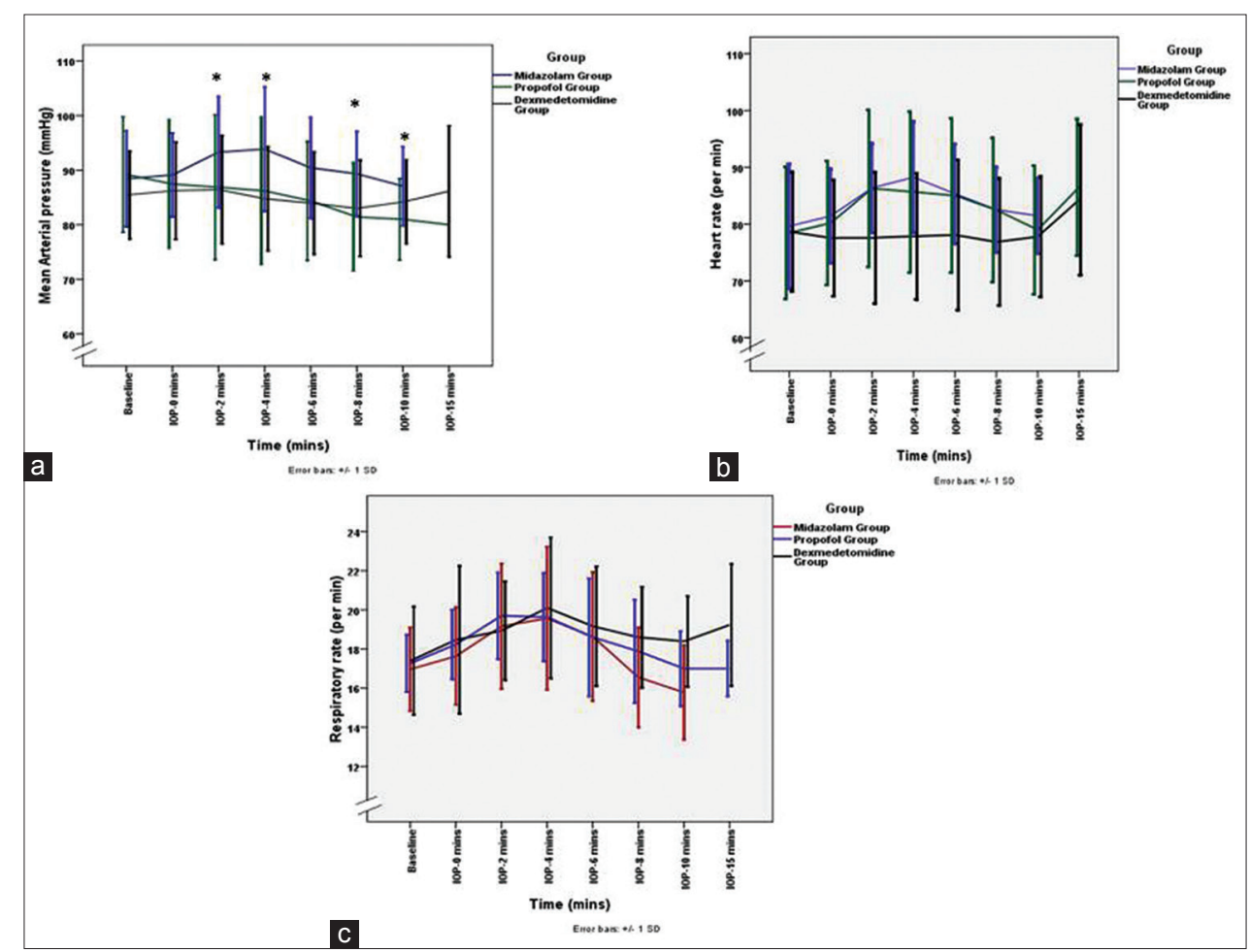

Figure 2: Hemodynamic changes (mean \pm standard deviation) in patients undergoing elective upper gastrointestinal endoscopy receiving midazolam, propofol and dexmedetomidine: (a) Mean arterial pressure, (b) Heart rate (c) Respiratory rate

\begin{tabular}{|c|c|c|c|c|}
\hline \multirow[t]{2}{*}{ Characteristics } & \multicolumn{3}{|c|}{ Sedation groups $(n=30)$} & \multirow[t]{2}{*}{$P$} \\
\hline & MDZ group & PF group & DEX group & \\
\hline Age (years) & $33.8 \pm 11$ & $34.8 \pm 10.1$ & $36.8 \pm 9.6$ & 0.52 \\
\hline Male/female (\%) & $18(60) / 12(40)$ & $17(56.7) / 13(43.3)$ & $19(63.3) / 11(36.7)$ & 0.87 \\
\hline Weight $(\mathrm{kg})$ & $59.9 \pm 11.9$ & $57 \pm 11.1$ & $62.4 \pm 12.2$ & 0.21 \\
\hline Height (cm) & $156.1 \pm 6.2$ & $154.8 \pm 6.9$ & $156.8 \pm 9.4$ & 0.13 \\
\hline ASA class $(I / I I)$ & $28(93.3) / 2(6.7)$ & $28(93.3) / 2(6.7)$ & $26(86.7) / 4(13.3)$ & 0.51 \\
\hline Baseline MAP (mmHg) & $88.4 \pm 8.7$ & $89.2 \pm 10.6$ & $85.4 \pm 8.0$ & 0.249 \\
\hline Baseline HR (beat/min) & $79.6 \pm 10.9$ & $78.4 \pm 11.6$ & $78.7 \pm 10.5$ & 0.908 \\
\hline Baseline RR (breath/min) & $16.9 \pm 2.1$ & $17.3 \pm 1.5$ & $17.4 \pm 2.8$ & 0.734 \\
\hline Baseline $\mathrm{SpO}_{2}(100 \%)$ & $99.9 \pm 0.2$ & $99.9 \pm 0.3$ & $100 \pm 0.0$ & 0.164 \\
\hline Duration of procedure (min) & $20 \pm 0$ & $12 \pm 4.7$ & $11 \pm 4$ & $0.03^{*}$ \\
\hline Dose of fentanyl used for breakthrough sedation $(\mathrm{mcg})$ & $20 \pm 10.2$ & $21.7 \pm 8.6$ & $19.2 \pm 10.8$ & 0.61 \\
\hline Willingness to undergo similar procedure in future, $n(\%)$ & $24(80)$ & $24(80)$ & $29(96.7)$ & 0.11 \\
\hline Patient satisfaction of VAS $1 / 10(\%)$ & 93.3 & 76.7 & 40 & $<0.001^{* *}$ \\
\hline Endoscopist satisfaction of VAS $1 / 10(\%)$ & 13.3 & 56.7 & 60 & $<0.001^{* *}$ \\
\hline Time to achieve modified aldrete score of $10 / 10(\mathrm{~min})$ & $18.3 \pm 3.8$ & $12.7 \pm 2.9$ & $7.7 \pm 3.9$ & $0.001^{\star *}$ \\
\hline
\end{tabular}

*Significant, **Highly significant, ANOVA test. ASA=American Society of Anesthesiologists, MAP=Mean arterial pressure, RR=Respiratory rate, HR=Heart rate, $\mathrm{SpO} 2=$ Oxygen saturation of haemoglobin, $\mathrm{VAS}=$ Visual analogue scale, MDZ=Midazolam, $\mathrm{PF}=$ Propofol

\section{Discussion}

The aim of this study was to compare the efficacy and safety of dexmedetomidine with propofol or midazolam use as sole sedoanalgesic in patients undergoing UGIE. The present study revealed that the dexmedetomidine is safer as it is associated with least hemodynamic perturbations and is more effective (as rate of desired sedation achieved was higher) than midazolam and propofol. Dexmedetomidine use was also linked with the fastest recovery and higher level of endoscopist satisfaction as compared to midazolam [Table 3].

Each sedative agent has unique pharmacokinetic properties and pharmacodynamic effects. Selection of a particular sedative agent by an anesthesiologist or endoscopist depends on knowledge of pharmacological properties of the agent, familiarity and experience with its use. Dexmedetomidine is a relatively newer sedative as compared to other anesthetic 
molecules. ${ }^{[8]}$ It was approved by the Food and Drug Administration, at the end of 1999 , for use in humans as a short-term medication $(<24 \mathrm{~h})$ for sedation/analgesia in the intensive care unit. Like other $\alpha-2$ adrenoceptor agonists, dexmedetomidine provides sedation, hypnosis, anxiolysis, amnesia and analgesia. The hypnotic effect of dexmedetomidine is mediated by the hyperpolarization of

\begin{tabular}{lcccc}
\hline \multicolumn{4}{l}{ Table 2: Adverse events during the procedure } \\
\hline Variables & \multicolumn{3}{c}{ Sedation groups $(\boldsymbol{n}=30)(\%)$} & $\boldsymbol{P}$ \\
\cline { 2 - 4 } & MDZ group & PF group & DEX group & \\
\hline Tachycardia $^{\mathrm{a}}$ & $15(50)$ & $10(33.3)$ & $9(30)$ & 0.231 \\
Hypotension $^{\mathrm{b}}$ & $3(10)$ & $7(23.3)$ & $3(10)$ & 0.933 \\
Bradycardia $^{\mathrm{c}}$ & $0(0)$ & $0(0)$ & $2(6.6)$ & NA \\
Arrhythmias $^{\text {Gag and discomfort }}$ & $0(0)$ & $1(3.3)$ & $0(0)$ & NA \\
Gay & $19(63.3)$ & $13(43.3)$ & $11(36.7)$ & 0.099 \\
\hline
\end{tabular}

Data are presented as $n(\%)$, a $\mathrm{HR}>100$ beats min or an increase of $>30$ beats min from baseline, ${ }^{b}$ Hypotension (MAP drop by $>20 \%$ of baseline), ${ }^{\circ} \mathrm{HR}$ of $<60 /$ min minor a decrease of $<15 /$ min from baseline noradrenergic neurons in the locus ceruleus of the brain stem (a small bilateral nucleus that contains many adrenergic receptors), which is a key site in modulating wakefulness. The locus ceruleus is also the site of origin for the descending medullo-spinal adrenergic pathway, which is known to be a key mechanism in regulating nociceptive neurotransmission. When these sites are stimulated, they decrease the firing of nociceptor neurons stimulated by peripheral $A$ and $C$ fibers and also inhibit the release of their neurotransmitters. Dexmedetomidine has a short onset of action (15 min) and is extensively metabolized in the liver through glucuronide conjugation and biotransformation by the cytochrome P450 enzyme system. There are no known active or toxic metabolites.

A bolus dose of $1 \mu \mathrm{g} / \mathrm{kg}$ results in an initial increase in blood pressure and a reflex drop in HR (due to stimulation of the $\alpha-2_{b}$ receptors in vascular smooth muscle). This initial response

\begin{tabular}{|c|c|c|c|c|c|}
\hline Author & $\begin{array}{l}\text { Country, year } \\
\text { of publication }\end{array}$ & $\begin{array}{l}\text { Study design, } \\
\text { subjects }\end{array}$ & $\begin{array}{l}\text { Drugs } \\
\text { compared }\end{array}$ & Main findings & Conclusions \\
\hline $\begin{array}{l}\text { Demiraran } \\
\text { et al. }{ }^{[10]}\end{array}$ & Turkey, 2007 & $\begin{array}{l}\text { Prospective } \\
\text { randomized } \\
\text { study, } \\
50 \text { patients } \\
\text { undergoing } \\
\text { UGIE }\end{array}$ & MDZ and DEX & $\begin{array}{l}\text { Retching and endoscopist satisfaction were } \\
\text { significantly different in patients receiving DEX } \\
\text { versus those receiving MDZ }(88.8 \pm 6.5 \text { vs. } 73.5 \pm 16.4 \text {, } \\
P<0.05 \text {; and } 20.6 \pm 4.4 \text { vs. } 45.2 \pm 6.0 ; P<0.001) \text {. In the } \\
\text { MDZ group, the number of patients who had adverse } \\
\text { effects was higher than the DEX group }(P<0.05)\end{array}$ & $\begin{array}{l}\text { DEX may be a good } \\
\text { alternative to MDZ to } \\
\text { sedate patients for } \\
\text { upper endoscopy }\end{array}$ \\
\hline $\begin{array}{l}\text { Vázquez- } \\
\text { Reta } \\
\text { et al. }{ }^{[11]}\end{array}$ & Mexico, 2011 & $\begin{array}{l}\text { Double } \\
\text { blind RCT, } \\
40 \text { patients } \\
\text { undergoing } \\
\text { UGIE }\end{array}$ & MDZ and DEX & $\begin{array}{l}\text { The DEX group had a shorter recovery time }(7.1 \mathrm{vs.} \\
15.8 \mathrm{~min}, P<0.05) \text { and satisfaction }(9.9 \mathrm{vs.} 9.0, \\
P<0.05) \text {. Adverse effects occurred in similar } \\
\text { proportions in both groups }\end{array}$ & $\begin{array}{l}\text { MDZ and DEX are } \\
\text { suitable for endoscopic } \\
\text { procedures of upper } \\
\text { digestive tract. DEX } \\
\text { offers shorter recovery } \\
\text { time and better } \\
\text { patient's satisfaction }\end{array}$ \\
\hline $\begin{array}{l}\text { Sethi } \\
\text { et al..112] }\end{array}$ & India, 2014 & $\begin{array}{l}\text { Open-label } \\
\text { RCT, } \\
60 \text { patients } \\
\text { undergoing } \\
\text { ERCP* }\end{array}$ & MDZ and DEX & $\begin{array}{l}\text { Patients receiving DEX had lower HR and facial } \\
\text { pain score at } 5,10 \text { and } 15 \text { min following the initiation } \\
\text { of sedation }(P<0.05) \text {. There was no statistically } \\
\text { significant difference in BP and respiratory rate. The } \\
\text { procedure elicited a gag response in } 29(97 \%) \text { and } \\
7(23 \%) \text { subjects in } \mathrm{MDZ} \text { group and dexmeditomidine } \\
\text { group respectively }(P<0.05) \text {. Modified Aldrete score } \\
\text { of } 9-10 \text { at } 5 \text { min during recovery was achieved in } \\
27(90 \%) \text { subjects in dexmeditomidine group in } \\
\text { contrast to } 5(17 \%) \text { in MDZ group }(P<0.05) \text {. DEX } \\
\text { showed higher patient and surgeon satisfaction } \\
\text { scores }(P<0.05)\end{array}$ & $\begin{array}{l}\text { DEX can be a superior } \\
\text { alternative to MDZ for } \\
\text { conscious sedation in } \\
\text { ERCP }\end{array}$ \\
\hline $\begin{array}{l}\text { Muller } \\
\text { et al..[13] }\end{array}$ & Brazil, 2008 & $\begin{array}{l}\text { Randomized, } \\
\text { blind, } \\
\text { double-dummy } \\
\text { clinical trial, } \\
\text { total } 26 \text { patients } \\
\text { undergoing } \\
\text { ERCP }\end{array}$ & $\begin{array}{l}\text { DEX alone and } \\
\text { propofol plus } \\
\text { fentanyl }\end{array}$ & $\begin{array}{l}\text { The RR was } 2.71(95 \% \mathrm{Cl}, 1.31-5.61) \text { and the } \\
\text { number of patients that NNT was } 1.85(95 \% \mathrm{Cl} \text {, } \\
1.19-4.21) \text { to observe one additional patient with } \\
\text { drowsiness } 15 \text { min after sedation in the DEX group. } \\
\text { Greater reduction in blood pressure, a lower heart } \\
\text { rate, and greater sedation after the procedure in } \\
\text { DEX group }\end{array}$ & $\begin{array}{l}\text { DEX was associated } \\
\text { with greater } \\
\text { hemodynamic } \\
\text { instability and a } \\
\text { prolonged recovery }\end{array}$ \\
\hline $\begin{array}{l}\text { Takimoto } \\
\text { et al. } .^{[14]}\end{array}$ & Japan, 2011 & $\begin{array}{l}\text { Randomized } \\
\text { study involving } \\
90 \text { patients } \\
\text { undergoing } \\
\text { ESD of gastric } \\
\text { cancer }\end{array}$ & $\begin{array}{l}\text { DEX, propofol } \\
\text { and MDZ }\end{array}$ & $\begin{array}{l}\text { None of the DEX-sedated patients showed a } \\
\text { significant reduction of the oxygen saturation level. } \\
\text { The rate of effective sedation was significantly higher } \\
\text { in the DEX group compared with the MDZ or PF } \\
\text { group. No DEX-sedated patient developed major } \\
\text { surgical complications }\end{array}$ & $\begin{array}{l}\text { Sedation with DEX is } \\
\text { effective and safe for } \\
\text { patients with gastric } \\
\text { tumors who are } \\
\text { undergoing ESD }\end{array}$ \\
\hline
\end{tabular}

$\mathrm{ERCP}=$ Endoscopic retrograde cholangiopancreatography, $\mathrm{DEX}=$ Dexmedetomidine, $\mathrm{BP}=\mathrm{Blood}$ pressure, $\mathrm{RR}=\mathrm{Relative}$ risk, $\mathrm{Cl}=\mathrm{Confidence}$ interval, $\mathrm{NNT}=\mathrm{Needed}$ to be treated, MDZ=Midazolam, PF=Propofol, GI=Gastrointestinal, UGIE=Upper gastrointestinal endoscopy, RCT=Randomized controlled trial, ESD=Endoscopic submucosal dissection 
lasts for 5-10 min that is followed by a slight decrease in blood pressure due to the inhibition of central sympathetic outflow. Despite profound sedative properties, dexmedetomidine is associated with only limited respiratory effects leading to a wide safety margin. ${ }^{[8]}$

The most important and most frequent side effect is bradycardia which can be managed with atropine, ephedrine, and volume infusion. Other notable side effects are hypertension, hypotension, nausea, atrial fibrillation, and hypoxia. Most of the adverse events associated with dexmedetomidine use occur during or shortly after loading dose. However, low bolus dosing, titrated maintenance rate of drug infusion, adequate volume repletion and careful patient selection and adequate monitoring may attenuate adverse cardiac side effects.

Hence, many clinicians might have qualms regarding safety profile of dexmedetomidine in endoscopic procedures mainly owing to its known adverse hemodynamic effects (particularly bradycardia and hypotension). ${ }^{[9]}$ Prior to initiation of this study, the investigators had similar concerns and therefore the use of dexmedetomidine was restricted. Propofol or midazolam along with ketamine was the commonest sedative regime used in different combination of doses at our institution.

In the present study, both dexmedetomidine and midazolam maintained stable hemodynamics throughout the procedure. Nevertheless, propofol group showed a significant drop in MAPs at various instances during UGIE. Seven patients developed hypotensive episodes that were treated with 100-200 mL of fluid blouses. This finding could be due to its narrow therapeutic window and also due to overdosing as duration was slightly longer in this group of patients. However, there was no statistically significant intergroup variability in other hemodynamic parameters $\left(\mathrm{HR}, \mathrm{SpO}_{2}\right.$ and $\mathrm{RR})$. There was no event of desaturation or apnea as only low doses of fentanyl were used as rescue analgesia. However, patients in the dexmedetomidine group required higher but statistically insignificant dose of fentanyl $(P=0.266)$. Contrary to our study, Muller et al. recorded greater hemodynamic instability (greater reduction in blood pressure and lower HR) associated with dexmedetomidine use, the reason for which could be due to inclusion of ASA class III patients. Another reason could be a larger dose of dexmedetomidine used due to prolonged procedural time as compared to our study (24 $\mathrm{min}$ vs. $10 \mathrm{~min}) .{ }^{[13]}$

Rate of desired sedation level was significantly higher in the dexmedetomidine group as compared to other two groups. Similarly, Takimoto et al. reported significantly higher rate of effective sedation in the dexmedetomidine group compared with the midazolam or propofol groups undergoing endoscopic mucosal resection of gastric tumors. ${ }^{[14]}$
Endoscopist satisfaction was significantly higher in patients receiving dexmedetomidine due to decreased rate of movement and gag reflex during procedure. Contrastingly, patient satisfaction seemed to be significantly higher in the midazolam group. This contradictory finding can be explained by amnestic property of midazolam as patients were interviewed within $1 \mathrm{~h}$ of completion of outpatient procedure. Similar observations were made by Demiraran et al. who noted higher level of endoscopist satisfaction in the dexmedetomidine group as compared to the midazolam group (VAS 88.8 vs. $73.5 ; P=0.029) .{ }^{[10]}$ A recent study from India also noted higher patient and endoscopist satisfaction scores in the dexmedetomidine group as compared to the midazolam group $(P<0.05) .{ }^{[12]}$ Significantly faster recovery was observed in the dexmedetomidine group that could be due to shorter duration of the procedure and low dose infusion. This result is in line with those reported in studies by Vázquez-Reta et al. and Takimoto et al. ${ }^{[11,14]}$

Similar to our finding, randomized controlled trial from Mexico done by Vázquez-Reta et al. reported no difference in adverse events between midazolam and dexmedetomidine group in UGIE. ${ }^{[11]}$ Though, all sedative drugs were safe to use during a UGIE, the importance of vigilant monitoring by a trained nurse or anesthetist cannot be ignored. Sedative-induced-hypotension can be prevented by pre-hydration with $100-200 \mathrm{~mL}$ intravenous fluid just prior to administration of UGIE.

There are some limitations in our study: Single center with small sample size which included stable ASA class I or II patients, therefore, our findings have external validity and cannot be extrapolated to the general population. In our study, the endoscopic procedures were simple, diagnostic and of short duration. Lengthy procedures are associated with more discomfort and retching as topical anesthetic applied once at the beginning of the procedure is short-lived. Therefore, future studies may be directed to study the comparative effectiveness of these agents involving patients undergoing lengthy procedures. We could not study the cost benefits ratio of these sedatives given the fact that dexmedetomidine is a relatively expensive drug, and affordability may limit its use. However, we believe that due to its wide safety profile in recommended doses, it can be used even by trained nurses and endoscopists as well, which may cut overall procedure cost per patient. Further studies are needed to address this issue. The robust design (randomized and double-blind) and consistency in data collection by single investigator eliminating the possibility of selection biases form the strengths of this study.

Dexmedetomidine as sole sedative is superior to midazolam and propofol in terms of safety and recovery time. The use of propofol was associated with hypotensive episodes that can be prevented by pre-hydration. All sedatives were similar with regard to adverse events. 


\section{Conclusion}

Use of dexmedetomidine was associated with greater hemodynamic stability and faster recovery as compared to propofol and midazolam. Endoscopists expressed a higher level of satisfaction with dexmedetomidine compared with other sedatives in this study. Multi-centric large clinical trials are required to confirm findings of this study so as to make dexmedetomidine first choice for conscious sedation among contemporary endoscopists.

\section{Acknowledgement}

We sincerely thank to Professor Thomas Alexander, Department of Gastroenterology, PIMS hospital, for his valuable suggestions at various steps of study and manuscript review.

\section{References}

1. de la Morena F, Santander C, Esteban C, de Cuenca B, García JA, Sánchez J, et al. Usefulness of applying lidocaine in esophagogastroduodenoscopy performed under sedation with propofol. World J Gastrointest Endosc 2013;5:231-9.

2. Ristikankare M, Julkunen R, Heikkinen M, Mattila M, Laitinen T, Wang SX, et al. Sedation, topical pharyngeal anesthesia and cardiorespiratory safety during gastroscopy. J Clin Gastroenterol 2006;40:899-905

3. Triantafillidis JK, Merikas E, Nikolakis D, Papalois AE. Sedation in gastrointestinal endoscopy: Current issues. World J Gastroenterol 2013;19:463-81.

4. Wang D, Chen C, Chen J, Xu Y, Wang L, Zhu Z, et al. The use of propofol as a sedative agent in gastrointestinal endoscopy: A meta-analysis. PLoS One 2013;8:e53311.

5. Lera dos Santos ME, Maluf-Filho F, Chaves DM, Matuguma SE, Ide E, Luz Gde O, et al. Deep sedation during gastrointestinal endoscopy:
Propofol-fentanyl and midazolam-fentanyl regimens. World J Gastroenterol 2013;19:3439-46.

6. Chernik DA, Gillings D, Laine H, Hendler J, Silver JM, Davidson AB, et al. Validity and reliability of the Observer's Assessment of Alertness/Sedation Scale: Study with intravenous midazolam. J Clin Psychopharmacol 1990;10:244-51.

7. Aldrete JA. Modifications to the postanesthesia score for use in ambulatory surgery. J Perianesth Nurs 1998;13:148-55.

8. Gertler R, Brown HC, Mitchell DH, Silvius EN. Dexmedetomidine: A novel sedative-analgesic agent. Proc (Bayl Univ Med Cent) 2001;14:13-21.

9. Bajwa S, Kulshrestha A. Dexmedetomidine: An adjuvant making large inroads into clinical practice. Ann Med Health Sci Res 2013;3:475-83.

10. Demiraran Y, Korkut E, Tamer A, Yorulmaz I, Kocaman B, Sezen G, et al. The comparison of dexmedetomidine and midazolam used for sedation of patients during upper endoscopy: A prospective, randomized study. Can J Gastroenterol 2007;21:25-9.

11. Vázquez-Reta JA, Jiménez Ferrer MC, Colunga-Sánchez A, Pizarro-Chávez S, Vázquez-Guerrero AL, Vázquez-Guerrero AR. Midazolam versus dexmedetomidine for sedation for upper gastrointestinal endoscopy. Rev Gastroenterol Mex 2011;76:13-8.

12. Sethi P, Mohammed S, Bhatia PK, Gupta N. Dexmedetomidine versus midazolam for conscious sedation in endoscopic retrograde cholangiopancreatography: An open-label randomised controlled trial. Indian J Anaesth 2014;58:18-24.

13. Muller S, Borowics SM, Fortis EA, Stefani LC, Soares G, Maguilnik I, et al. Clinical efficacy of dexmedetomidine alone is less than propofol for conscious sedation during ERCP. Gastrointest Endosc 2008;67:651-9.

14. Takimoto K, Ueda T, Shimamoto F, Kojima Y, Fujinaga Y, Kashiwa A, et al. Sedation with dexmedetomidine hydrochloride during endoscopic submucosal dissection of gastric cancer. Dig Endosc 2011;23:176-81.

How to cite this article: Samson S, George SK, Vinoth B, Khan MS, Akila B. Comparison of dexmedetomidine, midazolam, and propofol as an optimal sedative for upper gastrointestinal endoscopy: A randomized controlled trial. J Dig Endosc 2014;5:51-7.

Source of Support: Nil, Conflict of Interest: None declared. 